\title{
Segmental arterial mediolysis: differentiation of rare arteriopathy from vascular mimics
}

\author{
Alvin C Yiu, ${ }^{1}$ Ali Hussain 이, ${ }^{1}$ Matthew M Byrne, ${ }^{1}$ Rachel Villacorta-Lyew ${ }^{2}$
}

'Department of Internal Medicine, Tripler Army Medical Center, Honolulu, Hawaii, USA ${ }^{2}$ Department of Critical Care Medicine, Tripler Army Medical Center, Honolulu, Hawaii, USA

\section{Correspondence to Dr Alvin C Yiu; alvin.yiu921@gmail.com}

Accepted 10 August 2021

\section{DESCRIPTION}

A 49-year-old Hispanic woman with a previous medical history significant for stage I hypertension presented to the emergency department with acuteonset chest pain. She described her pain as sharp and non-exertional with radiation to the back. She denied headache, vision changes or abdominal pain. Her home medications included losartan, loratadine and vitamin $\mathrm{D}_{3}$. Her family and personal histories were negative for tobacco use, connective tissue diseases, early sudden cardiac death or vasculitis. She was mildly hypertensive and tachycardic to $140 / 90 \mathrm{~mm} \mathrm{Hg}$ and $100 \mathrm{bpm}$ on presentation. Physical examination did not reveal any skin lesions, skin discolouration or scalp tenderness. The patient received an abdominal CT aortogram, which showed a $9 \mathrm{~mm}$ pseudoaneurysm at the proximal common hepatic artery with irregular hepatic artery stenosis distal to the aneurysm without downstream ischaemic findings (figure 1). The renal arteries were normal. She was admitted for medical management of thoracic aortic disease and further workup for vascular aneurysmal syndromes. She received a CT angiogram of the head and neck to evaluate for further dissections, which revealed a $2 \mathrm{~cm}$ non-flow limiting dissection in the right common carotid artery (figure 2). Laboratory evaluation did not show elevation in erythrocyte sedimentation rate, cardiac troponin, liver associated enzymes, leucocyte count or anti-neutrophil cytoplasmic antibody (ANCA) titres. Complement levels were normal. She was diagnosed with segmental arterial mediolysis (SAM) and initially treated with intravenous esmolol and clevidipine drip infusion as anti-impulse therapy for thoracic aortic aneurysm with concomitant resolution of chest pain. She was subsequently transitioned to oral metoprolol succinate and losartan. She remained asymptomatic and was discharged home on hospital day 7 .

SAM is a rare, non-atherosclerotic, noninflammatory, degenerative vasculopathy

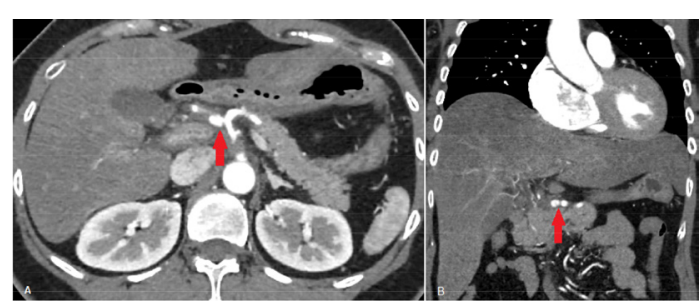

Figure 1 (A) Axial abdominal CT showing $9 \mathrm{~mm}$ pseudoaneurysm extending from the proximal common hepatic artery. (B) Coronal abdominal CT showing interior lumen of hepatic artery pseudoaneurysm.

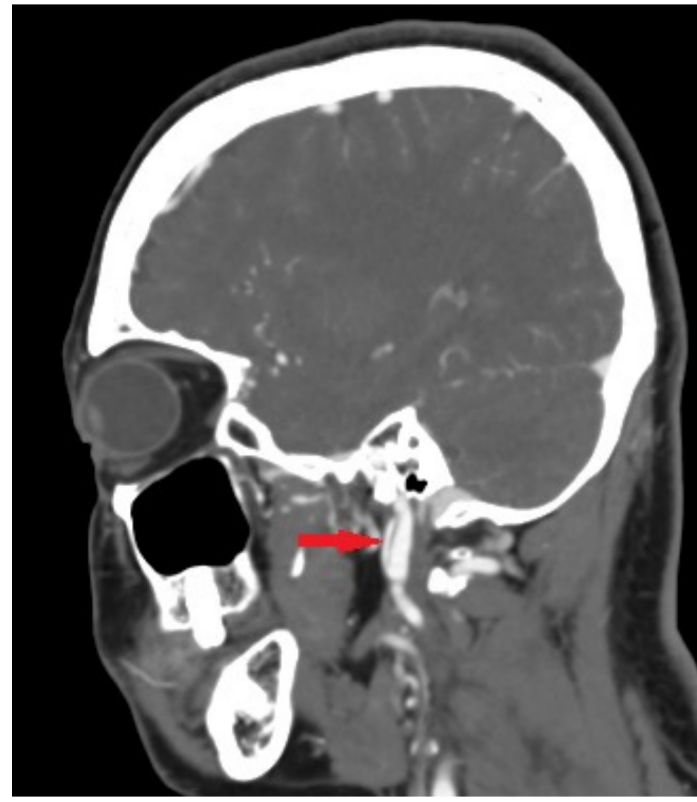

Figure 2 CT angiography of the head and neck showing a $2 \mathrm{~cm}$ non-flow limiting carotid dissection in the right upper common carotid artery.

characterised by lysis of the arterial medial layer, resulting in dissecting pseudoaneurysm, intramural haematoma and possible vessel rupture. ${ }^{12}$ Although biopsy and histopathological diagnosis are definitive, biopsy is not advised in patients whose aneurysmal pathology does not otherwise meet criteria for surgical intervention. ${ }^{3}$ Fortunately, SAM can be clinically diagnosed with a constellation of laboratory studies and clinical details that differentiate it from other vascular mimics. Serum inflammatory markers, complete blood count, ANCA titres

\section{Patient's perspective}

When I first learnt about my condition, I was scared. On one hand, I was relieved that my chest pain was not due to a heart attack. However, the words segmental arterial mediolysis sounded even worse. Luckily, the doctors and nurses who took care of me did an excellent job explaining to me in layman's terms the process that was going on inside my arteries and that I would need to be admitted for treatment of my blood pressure and heart rate to prevent worsening of the vessel 'outpouching'. I was happy that my chest pain resolved with treatment, and that I was able to go home on my oral medications. 


\section{Learning points}

Segmental arterial mediolysis (SAM) is a non-atherosclerotic, non-inflammatory degenerative vasculopathy characterised by lysis of the arterial medial layer, leading to dissecting pseudoaneurysm, intramural haematoma and possible vessel rupture.

- Providers should consider SAM as a diagnosis in the setting of multiple concomitant aneurysmal findings.

- A thorough history, physical, laboratory, radiological workup should be pursued to differentiate SAM from other autoimmune or connective tissue diseases.

and complement levels differentiate SAM from mimicking vasculitidies such as polyarteritis nodosa, ANCA-associated vasculitis, giant cell arteritis, Takaysu arteritis. ${ }^{34}$ Patient age, demographics and location of vascular findings should also be considered to differentiate SAM from familial connective tissue diseases and fibromuscular dysplasia (FMD). While FMD is also a non-inflammatory arterial disease, it presents in smaller arteries (renal, vertebral, extracranial) of Caucasian women aged 20-30 years old and often results in distal ischaemia due to vessel occlusion. ${ }^{35}$ However, SAM more commonly presents as aneurysmal findings occurring in medium to large arteries (mesenteric, carotid) of patients 40 years and older without gender or racial preference. ${ }^{3}$ Therefore, SAM presents with a different clinical profile compared with FMD and can diagnosed clinically. ${ }^{5}$ Our patient's demographics, presentation, laboratory and imaging were most consistent with SAM. We conclude by urging providers to consider SAM as a rare but dangerous diagnosis in patients with multiple aneurysmal findings.

Contributors AC-yY: conception of case, case research, writing of manuscript, editing of manuscript, submission of manuscript. $\mathrm{AH}$ : conception of case, case research, editing of manuscript. MMB: case research, editing of manuscript, RV-L: case research, patient care, editing of manuscript.

Funding The authors have not declared a specific grant for this research from any funding agency in the public, commercial or not-for-profit sectors.

Competing interests None declared.

Patient consent for publication Obtained.

Provenance and peer review Not commissioned; externally peer reviewed.

\section{ORCID iD}

Ali Hussain http://orcid.org/0000-0003-1830-4240

\section{REFERENCES}

1 Skeik N, Olson SL, Hari G, et al. Segmental arterial mediolysis (SAM): systematic review and analysis of 143 cases. Vasc Med 2019;24:549-63.

2 Pillai AK, Iqbal SI, Liu RW, et al. Segmental arterial mediolysis. Cardiovasc Intervent Radiol 2014;37:604-12.

3 Baker-LePain JC, Stone DH, Mattis AN, et al. Clinical diagnosis of segmental arterial mediolysis: differentiation from vasculitis and other mimics. Arthritis Care Res 2010;62:1655-60.

4 O'Shea J-P, Gordon S, Horak R, et al. Segmental arterial Mediolysis (SAM) leading to chronic renal insufficiency. Int J Nephrol Renovasc Dis 2021;14:117-23.

5 Ko M, Kamimura K, Sakamaki A, et al. Rare mesenteric arterial diseases: fibromuscular dysplasia and segmental arterial Mediolysis and literature review. Intern Med 2019;58:3393-400.

Copyright 2021 BMJ Publishing Group. All rights reserved. For permission to reuse any of this content visit

https://www.bmj.com/company/products-services/rights-and-licensing/permissions/

BMJ Case Report Fellows may re-use this article for personal use and teaching without any further permission.

Become a Fellow of BMJ Case Reports today and you can:

- Submit as many cases as you like

- Enjoy fast sympathetic peer review and rapid publication of accepted articles

- Access all the published articles

Re-use any of the published material for personal use and teaching without further permission

Customer Service

If you have any further queries about your subscription, please contact our customer services team on +44 (0) 2071111105 or via email at support@bmj.com.

Visit casereports.bmj.com for more articles like this and to become a Fellow 